\title{
Transpulmonary arterial repair of type 1 ventricular septal defect will induce pulmonary regurgitation: Appraisal of subpulmonic approach
}

\author{
Shao-Ju Chien, MD, ${ }^{\mathrm{a}}$ Jen-Ping Chang, MD, ${ }^{\mathrm{b}}$ Chi-Di Liang, MD, ${ }^{\mathrm{a}}$ Ying-Jui Lin, MD, ${ }^{\mathrm{a}}$ \\ Chien-Fu Huang, MD, ${ }^{\mathrm{a}}$ I-Chun Lin, $\mathrm{MD},{ }^{\mathrm{a}}$ and Chiung-Lun Kao, $\mathrm{MD}^{\mathrm{c}}$
}

Objective: A transpulmonary arterial approach to repair type I ventricular septal defect is the standard. However, the possible adverse effect on the pulmonary valve by this technique has not been investigated.

\begin{abstract}
Methods: A retrospective study reviewing type I ventricular septal defect repair from January 1991 to May 2010 was conducted. Of the 142 cases, the ventricular septal defect was repaired via the transpulmonary arterial route in 77 patients (54.2\%, PA group) and via the subpulmonic route in 65 patients (45.8\%, SP group). All patients received serial annual transthoracic color Doppler echocardiographic evaluation of pulmonary valve function.
\end{abstract}

\begin{abstract}
Results: The age at operation ranged from 1.2 to 272 months (median, 35.0 months; mean, 50.4 months). The mean follow-up period was 96.2 months (range, 2-234 months). Between the PA and SP groups, there was no significant difference in age, body weight, ventricular septal defect size, left to right shunt amount, mean pulmonary arterial pressure, and preoperative pulmonary stenosis or regurgitation. Postoperatively, there was no significant difference in the ejection fraction or incidence of residual ventricular septal defect, right bundle branch block, and pulmonary stenosis. However, the incidence of postoperative pulmonary regurgitation of more than moderate and the total scale of postoperative pulmonary regurgitation were both significantly higher in the PA group ( $16.9 \%$ vs $4.6 \%$ and $1.7 \pm 0.1$ vs $1.4 \pm 0.1, P=.031$ and .019 , respectively).
\end{abstract}

Conclusions: Although the transpulmonary arterial approach for type I ventricular septal defect repair has been advocated for decades, considering the adverse effect on pulmonary valve competency, the subpulmonic approach may be an alternative. (J Thorac Cardiovasc Surg 2011;142:1388-92)

Earn CME credits at

http://cme.ctsnetjournals.org

A transpulmonary arterial approach to repair type I ventricular septal defect (VSD) is the standard. ${ }^{1}$ However, the possible adverse effect on the pulmonary valve by traumatic downward stretching of the fragile pulmonary valve complex for exposure through the longitudinal pulmonary arteriotomy and the pulmonary annulus remains a concern. The fate of asymptomatic mild to moderate pulmonary regurgitation (PR) also remains a subject of debate, not only in patients after a valvotomy for isolated pulmonary valve stenosis but also in patients after repair of tetralogy of Fallot with

From the Division of Pediatric Cardiology ${ }^{\mathrm{a}}$ and Thoracic and Cardiovascular Surgery, ${ }^{\mathrm{b}}$ Kaohsiung Chang Gung Memorial Hospital, Chang Gung University, College of Medicine, Taiwan, Republic of China; and Division of Thoracic and Cardiovascular Surgery, ${ }^{\mathrm{c}}$ Chang Gung Memorial Hospital at Chiayi, Chang Gung Institute of Technology, Taiwan, Republic of China.

Disclosures: Authors have nothing to disclose with regard to commercial support.

Received for publication Nov 16, 2010; revisions received April 18, 2011; accepted for publication June 7, 2011; available ahead of print July 4, 2011.

Address for reprints: Jen-Ping Chang, MD, Division of Thoracic and Cardiovascular Surgery, Chang Gung Memorial Hospital-Kaohsiung Medical Center, 123, Ta Pei Rd, Niao Sung Hsiang, Kaohsiung, Taiwan, Republic of China 833 (E-mail: c9112772@adm.cgmh.org.tw).

0022-5223/\$36.00

Copyright (c) 2011 by The American Association for Thoracic Surgery doi:10.1016/j.jtcvs.2011.06.009 a transannular patch. ${ }^{2}$ Chronic right ventricular dysfunction due to significant PR may occur years after a successful surgical correction of tetralogy of Fallot. ${ }^{3-5}$ To avoid postoperative PR secondary to pulmonary valve complex manipulation, the subpulmonic transverse incision approach has been adopted for type I VSD repair in our practice since January 2000. This retrospective study was conducted to evaluate the long-term outcomes of pulmonary valve function after repair of type I VSD by 2 different approaches at the Chang Gung Memorial Hospital-Kaohsiung Medical Center.

\section{PATIENTS AND METHODS}

A retrospective study reviewing type I VSD repair from January 1991 to May 2010 was conducted. This study was approved by the institutional review board of Chang Gung Memorial Hospital-Kaohsiung Medical Center. In total, 145 patients with type I VSD received surgical correction. Three patients lost to follow-up were excluded. The diagnosis was made primarily on transthoracic 2-dimensional echocardiography, standard cardiac catheterization of both sides, and confirmed by surgical findings. Patients with associated major cardiovascular anomalies and significant aortic regurgitation were excluded.

\section{Definition of Type I Ventricular Septal Defect}

The classification of VSD is according to the nomenclature for VSD reviewed by The Society of Thoracic Surgeons in $2000 .^{6}$ Type I VSD is defined as the defect beneath the semilunar valve(s) in the conal or outlet septum, at the conal muscular or juxta-arterial position. Intraoperative direct measurement of the defect was performed, and the longer axis of the defect was used to represent the size of the VSD. 


$$
\begin{aligned}
& \text { Abbreviations and Acronyms } \\
& \qquad \text { CI }=\text { confidence interval } \\
& \text { PA }=\text { transpulmonary artery approach } \\
& \text { PR }=\text { pulmonary regurgitation } \\
& \text { SP }=\text { subpulmonic approach } \\
& \text { TR }=\text { tricuspid regurgitation } \\
& \text { VSD }=\text { ventricular septal defect }
\end{aligned}
$$

\section{Echocardiographic and Clinical Assessment}

All 142 patients randomly received serial annual transthoracic color Doppler echocardiographic evaluation by 4 pediatric cardiologists. The PR was assessed from continuous-wave Doppler tracing and color-flow mapping with visualization of the right ventricular outflow tract to depict the pulmonary valve and main pulmonary artery. The pulmonary artery and right ventricle were demonstrated in the parasternal short-axis view at the third intercostal space, and the image of PR flow was visualized in color and frozen when the regurgitant flow was visualized maximally at the level of the pulmonary valve. ${ }^{7,8}$ The PR was judged to be present by color Doppler if red, yellow, or mosaic signals were seen originating from the pulmonary valve or main pulmonary artery spreading into the right ventricular outflow tract during diastole. Color Doppler grading of PR severity was by jet width to pulmonary annulus width ratio, similar to color Doppler quantification for the aortic regurgitation as mild $(<0.2)$, moderate $(0.2-0.5)$, or severe $(>0.5){ }^{9-11}$ Continuous-wave Doppler waveforms were collected from the parasternal short-axis view guided by 2-dimensional, color Doppler, and audible and visible spectral data. A sampling theta angle of less than 20 degrees was used without angle correction. Many trivial (brief and narrow) color Doppler PR jets had no usable Doppler spectra. Only patients with analyzable Doppler spectra were included in the study. We also studied tricuspid regurgitation (TR) by color and continuous-wave Doppler. TR severity was assessed semiquantitatively by color Doppler jet area to right atrial area ratio as mild $(<20 \%)$, moderate $(20 \%-50 \%)$, and severe $(>50 \%)$. Right ventricular systolic pressure was calculated from the TR jet velocity. ${ }^{10}$

In addition to the transthoracic 2-dimensional echocardiograms, clinical evaluations for right heart function and 12-lead electrocardiograms were obtained annually. The incidence of greater than moderate PR and total scale of PR severity at the end point (July 31,2010) of the data collection were used in the outcome analysis.

\section{Statistical Analysis}

Statistical analysis was performed using SPSS for Windows software system, Version 13.0 (SPSS Inc, Chicago, Ill). Estimated rates of freedom from moderate PR were determined by the Kaplan-Meier product-limit method with $70 \%$ confidence intervals (CIs). Results are expressed as mean \pm standard deviation. Continuous variables were compared using the Student $t$ test. Categoric data were expressed as proportions and compared using the chi-square test or Fisher exact test.

\section{RESULTS}

\section{Demographics and Operative Procedure}

The study population consisted of 142 patients ( 87 male and 55 female) with type I VSD. Age at surgery ranged from 1.2 to 272 months (mean age, 50.4 months), and body weight ranged from 2.8 to $56.8 \mathrm{~kg}$ (mean, $16.4 \mathrm{~kg}$ ). Fortysix patients had associated minor congenital anomalies (small atrial septal defects in 37 , coarctation of the aorta
TABLE 1. Demographics of the two groups

\begin{tabular}{lrrr}
\hline & $\begin{array}{c}\text { PA group } \\
(\mathbf{n}=\mathbf{7 7})\end{array}$ & $\begin{array}{c}\text { SP group } \\
(\mathbf{n}=\mathbf{6 5})\end{array}$ & $\begin{array}{c}\boldsymbol{P} \\
\text { value }\end{array}$ \\
\hline Sex (male) & $46(59.7 \%)$ & $41(63.1 \%)$ & .684 \\
Age at operation (mo) & $57.1 \pm 6.2$ & $42.3 \pm 5.1$ & .067 \\
Body weight & $18.2 \pm 1.4$ & $14.9 \pm 1.2$ & .079 \\
VSD size & $10.0 \pm 0.6$ & $9.4 \pm 0.6$ & .490 \\
Qp/Qs & $1.6 \pm 0.1$ & $1.9 \pm 0.1$ & .159 \\
Mean pulmonary arterial pressure & $20.1 \pm 1.0$ & $20.5 \pm 1.8$ & .846 \\
\hline
\end{tabular}

$P A$, Transpulmonary artery approach; $Q p / Q s$, ratio of pulmonary to systemic blood flow; $S P$, subpulmonic approach.

in 2, patent ductus arteriosus in 2, atrial septal defect with coarctation of the aorta in 1, atrial septal defects with patent ductus arteriosus and coarctation of the aorta in 3 , and patent ductus arteriosus with coarctation of the aorta in 1). The mean size of the VSD was $9.8 \pm 0.6 \mathrm{~mm}$ (range, 2-30 mm). The mean ratio of pulmonary to systemic blood flow was $1.8 \pm 0.1$, and pulmonary artery pressure was $20.3 \pm 1.5$ mm Hg (Table 1).

Surgical repair was done via a transpulmonary arterial route in 77 patients $(54.2 \%$, PA group) and a subpulmonic route in 65 patients $(45.8 \%$, SP group). In the PA group, the type I VSD was repaired through a longitudinal pulmonary arteriotomy. The anterior pulmonary valve and the anterior part of the pulmonary annulus were retracted caudally and through the pulmonary valve orifice; the type I VSD was patched with a piece of knitted Dacron patch (Figure 1, A). In the SP group, the patients were selected by surgeon's preference. The type I VSD was repaired via a minimal transverse incision $2 \mathrm{~mm}$ below and parallel to the pulmonary annulus. During the subpulmonic incision, special attention was paid to avoid any injury to the pulmonary valve (Figure 1, B). In both groups, the VSD was repaired with a piece of pear-shape knitted Dacron patch with polypropylene running suture. The upper half of the patch was sutured with stitches passing through the posterior pulmonary annulus to the zone of ventriculoarterial junction. The lower half of the patch was sutured to the rim of the VSD. The demographics of the 2 groups are shown in Table 1. There was no difference in sex, age at operation, body weight, VSD size, ratio of pulmonary to systemic blood flow, and mean pulmonary arterial pressure between these 2 groups.

\section{Follow-up and Long-Term Outcomes}

The 142 patients were regularly followed (2-234 months; mean, 96.2 months). Residual VSD was noted in 4 patients, and 5 patients had moderate to severe postoperative tricuspid valve regurgitation at long-term follow-up. Mild residual pulmonary stenosis was noted in 19 patients. All of these parameters showed no significant difference between the 2 groups (Table 2). 

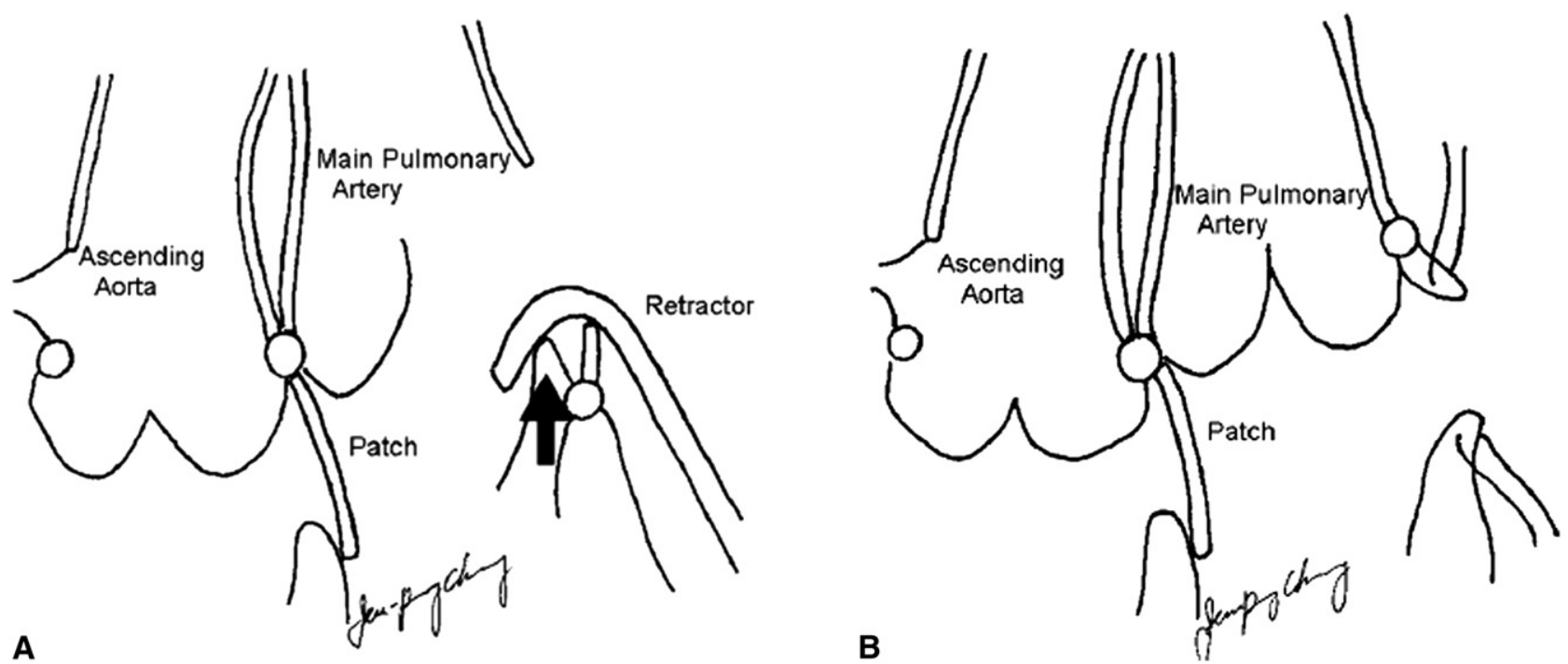

FIGURE 1. A, Type I VSD was repaired via a longitudinal pulmonary arteriotomy in the PA group. The anterior pulmonary valve and anterior part of the pulmonary annulus were retracted caudally (black arrow). Via the pulmonary valve orifice, the type I VSD was patched with a piece of Dacron knitted patch. $\mathrm{B}$, Type I VSD was repaired via a minimal transverse incision $2 \mathrm{~mm}$ below and parallel to the pulmonary annulus in the SP group.

\section{Pulmonary Regurgitation Issues}

The incidence of postoperative PR of more than moderate degree was significantly higher in the PA group $(16.9 \%$ vs $4.6 \%, P=.031)$. The onset of more than moderate $P R$ in the PA group was at $62.3 \pm 8.0$ months (range, 33-114 months) postoperatively. The total scale of postoperative PR in the PA group showed a significantly higher PR scale than the SP group $(1.7 \pm 0.1$ vs $1.4 \pm 0.1 . P=.019)$. The Kaplan-Meier curve comparing the 2 groups for freedom from significant PR across time showed a significant difference $(P=.048)$ (Figure 2$)$. The calculated freedom from moderate PR at 10 years is $94.7 \%$ in the SP group $(70 \%$ CI, 91.6-97.8) and $80.4 \%$ in the PA group (70\% CI,

TABLE 2. Surgical outcomes in the two groups

\begin{tabular}{lccc}
\hline & $\begin{array}{c}\text { PA group } \\
(\mathbf{n}=\mathbf{7 7})\end{array}$ & $\begin{array}{c}\text { SP group } \\
(\mathbf{n}=\mathbf{6 5})\end{array}$ & $\begin{array}{c}\boldsymbol{P} \\
\text { value }\end{array}$ \\
\hline Follow-up period & $120.0 \pm 6.2$ & $67.1 \pm 6.4$ & $<.0001$ \\
Postoperative PR $>3+$ & $13(16.9 \%)$ & $3(4.6 \%)$ & .031 \\
Total scale of postoperative PR & $1.7 \pm 0.1$ & $1.4 \pm 0.1$ & .019 \\
Postoperative TR $>3+$ & $4(5.2 \%)$ & $1(1.5 \%)$ & .375 \\
Postoperative PVPG 25-50 mm Hg & $1(1.3 \%)$ & $3(4.6 \%)$ & .332 \\
Postoperative PVPG $<25 \mathrm{~mm} \mathrm{Hg}$ & $8(10.4 \%)$ & $7(10.8 \%)$ & 1.000 \\
Total scale of postoperative TR & $1.7 \pm 0.1$ & $1.6 \pm 0.1$ & .593 \\
Vmax of postoperative TR & $2.2 \pm 0.1$ & $2.2 \pm 0.0$ & .894 \\
Residual VSD & $2(2.6 \%)$ & $2(3.1 \%)$ & 1.000 \\
EF of LV (\%) & $67.2 \pm 0.8$ & $66.8 \pm 0.7$ & .719 \\
RBBB & $4(5.2 \%)$ & $4(6.2 \%)$ & 1.000 \\
V tachyarrhythmias & 0 & 0 & 1.000 \\
\hline
\end{tabular}

$E F$, Ejection fraction; $L V$, left ventricle; $P A$, transpulmonary artery approach; $P R$, pulmonary regurgitation; $P S$, pulmonary stenosis; $P V P G$, pulmonary valve pressure gradient; $R B B B$, right bundle branch block; $S P$, subpulmonic approach; $T R$, tricuspid regurgitation; $V$, ventricular; Vmax, maximal jet velocity.
75.2-85.6). The total scale and velocity of postoperative TR, ejection fraction, and incidence of right bundle branch block were not significantly different between the 2 groups. It is noteworthy that no episode of ventricular tachyarrhythmias or symptom and sign of right ventricular failure was documented in both groups (Table 2).

\section{DISCUSSION}

Type I VSD is relatively common among Asians. The incidences of aortic cusp prolapse and aortic regurgitation have been reported as high as $36 \%$ to $79 \%$ and $52 \%$ to $78 \%$, respectively. ${ }^{12-14}$ Therefore, early surgical repair of the defect has been advocated. ${ }^{15,16}$ The transpulmonary arterial approach for repairing type I VSD is currently a standard. ${ }^{1}$ This approach had been advocated for avoiding postoperative right ventricular dysfunction and late ventricular tachyarrhythmias originating from the right ventriculotomy scar. ${ }^{17,18}$ However, the possible adverse effect on the pulmonary valve by traumatic downward stretching of the fragile pulmonary valve complex for exposure through the longitudinal pulmonary arteriotomy and the pulmonary annulus remains ignored. There is no report regarding the late PR and related adverse results after transpulmonary arterial closure of type I VSD.

The fate of asymptomatic mild to moderate PR also remains a subject of debate, not only in patients after a valvotomy for isolated pulmonary valve stenosis but also in patients after a repair of tetralogy of Fallot with a transannular patch. ${ }^{2}$ Chronic right ventricular dysfunction due to significant PR may occur years after a successful surgical correction of tetralogy of Fallot. ${ }^{3-5}$ Although these studies 
Kaplan-Meier event-free curve for moderate PR in groups PA and SP

Log rank analysis showed a significant difference, with $\mathrm{P}=0.048$

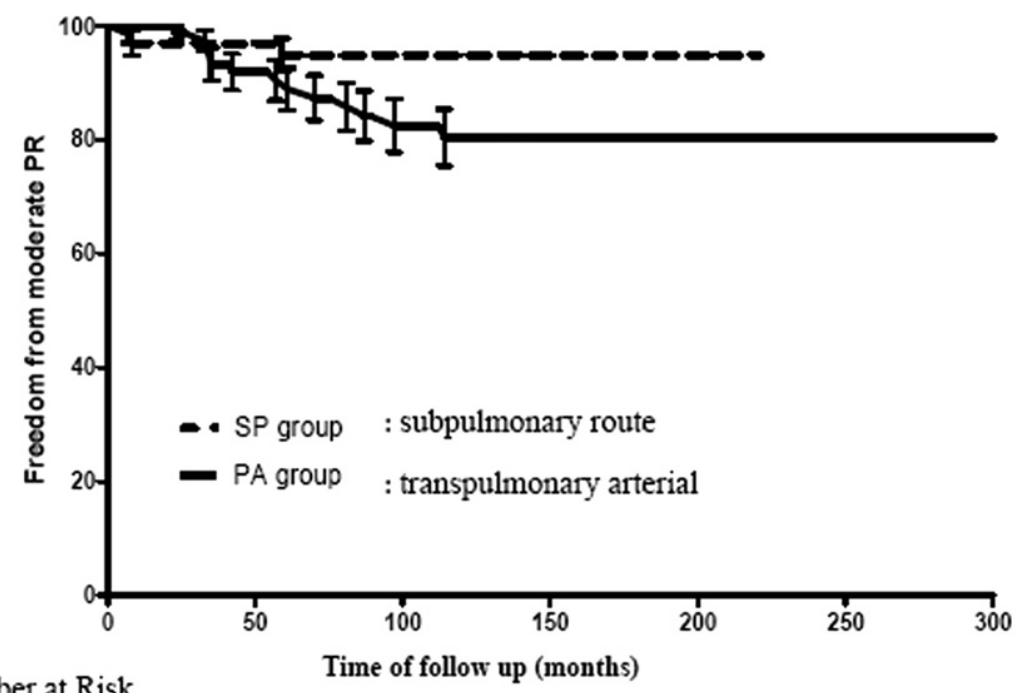

Number at Risk

\begin{tabular}{|l|l|l|l|l|l|l|l|}
\hline months & 0 & 50 & 100 & 150 & 200 & 250 & 300 \\
\hline PA group & 77 & 64 & 48 & 16 & 2 & 1 & 1 \\
\hline SP group & 65 & 50 & 30 & 13 & 3 & 0 & 0 \\
\hline
\end{tabular}

FIGURE 2. Kaplan-Meier curve comparing the 2 groups for freedom from significant $P R$ across time shows significant difference $(P=.048)$. Error bars indicate $70 \%$ CIs. $P A$, Transpulmonary artery approach; $P R$, pulmonary regurgitation; $S P$, subpulmonic approach.

of long-term deleterious effects of PR are of patients with tetralogy of Fallot and not of patients with type I VSD closure, to avoid the possible postoperative PR secondary to the pulmonary valve complex traction, subpulmonic transverse incision has been adopted for type I VSD repair in our practice since January 2000.

In our study, the incidence of postoperative PR of more than moderate degree was significantly higher in the PA group $(16.9 \%$ vs $4.6 \%, P=.031)$. The total scale of postoperative PR in the PA group showed a significantly higher PR scale than in the SP group $(1.7 \pm 0.1$ vs $1.4 \pm 0.1$. $P=.019)$. Although the manifestation suggesting the right ventricular volume overload was not documented in the PA group, the possible late deleterious effects produced by the long-standing PR, including diminished exercise tolerance, deterioration in biventricular function, ${ }^{17}$ ventricular tachyarrhythmias, and sudden death, are the issues of concern. ${ }^{18}$

When PR is significant, progressive right ventricular dilation and failure refractory to medical management will be inevitable. Significant PR is also an important cause of morbidity and even mortality necessitating eventual pulmonary valve implantation. ${ }^{19-21}$ Therefore, the deteriorating fate of the right ventricle and possible need of pulmonary valve implantation in patients after transpulmonary arterial repair of type I VSD will be the critical issues in the future. The onset of significant PR in the PA group was at $62.3 \pm 8.0$ months in our study. Thus, in the patients who received transpulmonary closure of type I VSD, careful echocardiographic follow-up for more than 6 years is strongly recommended.

Our study demonstrated a higher risk of PR in the PA group. However, the detailed mechanism of this late complication still remained unclear. The anterior pulmonary cusp, lateral, and medial pulmonary valve commissures are all thin and fragile. Because the only difference in these 2 groups is the method of approach, it is reasonable to speculate that during the downward traction of these vulnerable structures for exposure through the longitudinal pulmonary arteriotomy, some occult injuries seem inevitable.

Comprehensively, in addition to the PR issue, there is no significant demerit observed in the SP group regarding the ventricular performance and incidence of residual shunt and right bundle branch block. In this long-term cohort, there has been no episode of sudden death or ventricular tachyarrhythmia in either group. These outcomes support our strategy of adopting the subpulmonic approach instead of transpulmonary repair for type I VSD.

\section{Study Limitations}

Three main limitations of our study must be considered. First, the retrospective nature of this analysis and the lack of patient randomization are inherent flaws in the study design. 
Second, we acknowledge that both series of patients were consecutive and not contemporaneous. The subpulmonic route was the surgeon's biased preference. However, this type of flaw seems inevitable for a clinical study investigating the procedural evolution in 2 separate eras. Third, we acknowledge there is a significant discrepancy in the follow-up periods between the PA group $(120.0 \pm 6.2$ months) and the SP group (67.1 \pm 6.4 months). Thus, a longer follow-up of more than 100 months in the future will be necessary and conclusive to determine the fate of the SP group.

\section{CONCLUSIONS}

Although the transpulmonary arterial approach to repair type I VSD had been advocated for decades, considering the adverse effect on pulmonary valve competency of transpulmonary arterial approach, the subpulmonic approach may be a good alternative.

\section{References}

1. Tharion J, Cartmill TB, Johnson DC, Celermajer JM. Transpulmonary arterial repair of supracristal ventricular septal defects in infancy. $J$ Thorac Cardiovasc Surg. 1980;80:948-50.

2. Dodge-Khatami A, Tulevski II, Hitchcock JF, de Mol BAJM, Bennink GBWE. Neonatal complete correction of tetralogy of Fallot vs shunting and deferred repair: is the future of the right ventriculo-arterial junction at stake, and what of it? Cardiol Young. 2001;11:484-90.

3. Kavey RE, Thomas FD, Byrum CJ, Blackman MS, Sondheimer HM, Bove EL. Ventricular arrhythmias and biventricular dysfunction after repair of tetralogy of Fallot. J Am Coll Cardiol. 1984;4:126-31.

4. March HW, Ross JK, Weirich WL, Gerbode F. The influence of the ventriculotomy site on the contraction and function of the right ventricle. Circulation. 1961; 24:572-7.

5. Miura T, Nakano S, Shimazaki Y, Kobayashi J, Hirose H, Sano T, et al. Evaluation of right ventricular function by regional wall motion analysis in patients after correction of tetralogy of Fallot. Comparison of transventricular and nontransventricular repairs. J Thorac Cardiovasc Surg. 1992;104:917-23.
6. Jacobs JP, Burke RP, Quintessenza JA, Mavroudis C. Congenital heart surgery nomenclature and database project: ventricular septal defect. Ann Thorac Surg. 2000;69:S25-35.

7. Kobayashi J, Nakano S, Matsuda H, Arisawa J, Kawashima Y. Quantitative evaluation of pulmonary regurgitation after repair of tetralogy of Fallot using real-time flow imaging system. Jpn Circ J. 1989;53:721-7.

8. Yang H, Pu M, Chambers CE, Weber HS, Myers JL, Davidson WR Jr. Quantitative assessment of pulmonary insufficiency by Doppler echocardiography in patients with adult congenital heart disease. J Am Soc Echocardiogr. 2008;21: 157-64.

9. Perry GJ, Helmcke F, Nanda NC, Byard C, Soto B. Evaluation of aortic insufficiency by Doppler color flow mapping. J Am Coll Cardiol. 1987;9:952-9.

10. Bigras JL, Boutin C, McCrindle BW, Rebeyka IM. Short-term effect of monocuspid valves on pulmonary insufficiency and clinical outcome after surgical repair of tetralogy of Fallot. J Thorac Cardiovasc Surg. 1996;112:33-7.

11. Justo RN, McCrindle BW, Benson LN, Williams WG, Freedom RM, Smallhorn JF. Aortic valve regurgitation after surgical versus percutaneous balloon valvotomy for congenital aortic valve stenosis. Am J Cardiol. 1996;77: 1332-8.

12. Momma K, Toyama K, Atsuyoshi T. Natural history of subarterial infundibular ventricular septal defect. Am Heart J. 1984;108:1312-7.

13. Tohyama K, Satomi G, Momma K. Aortic valve prolapse and aortic regurgitation associated with subpulmonic ventricular septal defect. Am J Cardiol. 1997;79: 1285-9.

14. Komai H, Naito Y, Fujiwara K, Noguchi Y, Nishimura Y, Uemura S. Surgical strategy for doubly committed subarterial ventricular septal defect with aortic cusp prolapse. Ann Thorac Surg. 1997;64:1146-9.

15. Hitchcock JF, Suijker WJL, Ksiezycka E. Management of ventricular septal defect with associated aortic incompetence. Ann Thorac Surg. 1991;52:70-3.

16. Schmidt KG, Cassidy SC, Silverman NH, Stanger P. Doubly committed subarterial ventricular septal defect: echocardiographic features and surgical implications. J Am Coll Cardiol. 1988;12:1538-46.

17. Bove EL, Byrum CJ, Thomas FD, Kavey REW, Sondheimer HM, Blackman M. The influence of pulmonary insufficiency on ventricular function following repair of tetralogy of Fallot. J Thorac Cardiovasc Surg. 1983;85:691-6.

18. Zahka KG, Horneffer PJ, Rowe SA, Neill CA, Manolio TA, Kidd L. Long-term valvular function after total repair of tetralogy of Fallot: relation to ventricular arrhythmias. Circulation. 1988;78:III14-9.

19. Misbach GA, Turley K, Ebert PA. Pulmonary valve replacement for regurgitation after repair of tetralogy of Fallot. Ann Thorac Surg. 1983;36:684-91.

20. Therrien J, Siu SC, McLaughlin PR, Liu PP, Williams WG, Webb GD. Pulmonary valve replacement in adults late after repair of tetralogy of Fallot: are we operating too late? J Am Coll Cardiol. 2000;36:1670-5.

21. Warner KG, Anderson JE, Fulton DR, Payne DD, Geggel RL, Marx GR. Restoration of the pulmonary valve reduces right ventricular volume overload after previous repair of tetralogy of Fallot. Circulation. 1993;88:II189-97. 